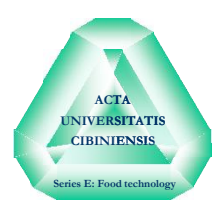

\title{
STUDY ON TRANSPORT PACKAGES USED FOR FOOD FRESHNESS PRESERVATION BASED ON ANSYS THERMAL ANALYSIS
}

\author{
Ying $\mathrm{YU}^{1}$ \\ Hunan Vocational College of Railway Technology, Zhuzhou, Hunan, 412000, \\ China
}

\begin{abstract}
In recent years, as the Chinese consumption level increases, the consumption quantity of high-value fruits, vegetables and seafood products have been increasing year by year. As a consequence, the traffic volume of refrigerated products also increases yearly and the popularization degree of the cold-chain transportation enhances. A low-temperature environment should be guaranteed during transportation, thus there is about $40 \%$ of diesel oil should be consumed by the refrigerating system and the cold-chain transportation becomes very costly. This study aimed to explore a method that could reduce the cost of transport packages of refrigerated products. On the basis of the heat transfer theory and the fluid mechanics theory, the heat exchange through corrugated cases during the operation of refrigerating system was analyzed, the heat transfer process of corrugated cases and refrigerator van was theoretically analyzed and the heat balance equation of corrugated cases was constructed. Besides, this study simulated the temperature field of the corrugated box during transportation. The temperature of the goods was changed through different cooling temperature to calculate the minimum energy consumption, so as to achieve the best refrigeration transport packaging program.
\end{abstract}

Keywords: Heat transfer theory; logistics transportation; ANSYS FLOTRAN; temperature distribution

\section{INTRODUCTION}

China is a country with a large production of agricultural products, and the trade volume of agricultural products in China is increasing gradually year by year. Fresh food takes a great proportion of demand in market; however, due to the neglect of transport caused by excessive emphasis on production,

${ }^{1}$ Corresponding author. Mailing address: Ying Yu, Hunan Vocational College of Railway Technology, No. 171, Middle Jianshe Road, Zhuzhou, Hunan, 412000, China. E-mail: yingyu23y@sina.com 
the development of fresh food transport is limited severely (Zhang et al., 2013; Zhang et al., 2011; Wang et al., 2012). Continually increasing consumption of high-value fruits, vegetables and seafood products has resulted in the increase of traffic volume of refrigerated products. The increase of cold-chain demand has been particularly outstanding in the fields of meet products, fruits and vegetables, dairy products and medicine (Tan and Zhang, 2014; Jia, 2013; Net et al., 2003). Temperature control of products is the key during the whole process of cold-chain transportation and any phenomenon of out-of-control temperature can lead to enormous losses (Yue et al., 2013; Liu et al., 2010; Jedermann et al., 2009). Thus, the temperature should be controlled precisely to guarantee the quality of products during transportation. Therefore, changes and field distribution of temperatures of the interior carriage and packing cases of products during transportation should be analyzed. The final results have great guidance values to the design of transport packages of products.

Lots of research results of the temperature field of refrigerated products have been obtained in foreign countries. Initial researches were mostly performed by experiments. Researchers in Italy once carried out experiments based on the railway, and various kinds of standardizing components were used to simulate product models, thus to analyze the temperature distribution of interior packages. As the computer technology develops rapidly at present, the temperature filed has been studied using numerical simulation. Quarini and Foster studied the heat exchange between the cold air of freezer and the outside, and the obtained results were of great value to the design of energy-efficient refrigerators. In this study, ANSYS FLOTRAN software was used to simulate temperature changes of products inside the refrigerator van, and the temperature field and temperature changes of the whole van were obtained. At last, obtained results were concluded, and improved cryogenic temperature and refrigerating method that could reduce energy consumption and save costs were planned, thus to obtain the optimal transportation program.

\section{MODEL OF PHASE CHANGE HEAT TRANSFER}

\section{Basic theories of heat transfer theory}

Fourier law is a fundamental law of heat transfer theory (Jaremkiewicz, 2014; Mikielewicz et al., 2014; Vasiliev et al., 2015), which can be described as follow: in phenomena of heat conduction, suppose the heat quantity that passes through the interface in unit time is in direct proportion to the change rate of temperature in vertical direction of the interface as well as to the area of the interface, then the direction of heat transfer is contrary to the direction of the temperature increase (Mikielewicz et al., 
2012). According to the Fourier law, the quantity of heat conduction $\Phi$ that passes through one position in unit time should be in direct proportion to the change rate of temperature as well as the area of the position:

$$
\begin{aligned}
& \Phi=-\lambda A \frac{d t}{d x}=\lambda A \frac{\Delta t}{\delta} \\
& q=\frac{\Phi}{A}=\lambda \frac{\Delta t}{\delta}
\end{aligned}
$$

In above equations, $\Phi$ refers to the heat flux (W); $\lambda$ refers to the thermal conductivity coefficient $(\mathrm{W} /(\mathrm{mK}))$; $t$ means temperature $(\mathrm{K}) ; x$ is the coordinate on heat conduction surface (m); ${ }^{q}$ refers to the heat flux that transfers along the $\mathrm{x}$ direction $\left(\mathrm{W} / \mathrm{m}^{2}\right) ; A$ is heat conduction area; $\Delta t$ is the temperature difference of surface $(\mathrm{K}) ; d t / d x$ is the temperature gradient in the direction of $x$, i.e., the change rate of temperature (the negative sign in equation 1 means that, the heat transfer direction is contrary to the direction of the temperature gradient); $\delta$ is the thickness of surface (m).

\section{ANSYS THERMAL ANALYSIS}

Using ANSYS software for thermal analysis is to apply the principle of conservation of energy to construct the heat balance equation and obtain the temperature of each node through finite element calculation; other thermal physics parameters of the material can be educed according to temperatures of nodes. Steady-state analysis and transient analysis can be performed.

\section{ANSYS thermal analysis governing equation}

The governing differential equation of heat conduction:

$$
\begin{aligned}
& \frac{\partial}{\partial x}\left(k_{x x} \frac{\partial T}{\partial x}\right)+\frac{\partial}{\partial y}\left(k_{y y} \frac{\partial T}{\partial y}\right)+\frac{\partial}{\partial z}\left(k_{z z} \frac{\partial T}{\partial z}\right)+q=\rho c \frac{d T}{d t} \\
& \frac{d T}{d t}=\frac{\partial T}{\partial t}+V_{x} \frac{\partial T}{\partial x}+V_{y} \frac{\partial T}{\partial y}+V_{z} \frac{\partial T}{\partial z}
\end{aligned}
$$

In the equation, $V_{x}, V_{y}$ and $V_{z}$ refer to conduction rates, and the equation can be transformed into equivalent integral form:

$$
\int_{v o l}\left[\rho c \delta_{T}\left(\frac{\partial T}{\partial t}+\{v\}^{T}\{L\}^{T}\right)+\{L\}^{T} \delta_{T}\left(\left\{D_{S}\{L\}^{T}\right)\right] d(v o\rangle^{\prime}=\int_{S_{2}} \delta T^{*} d\left(S_{2}\right)+\int_{S_{3}} \delta T h_{f}\left(T_{B}-T\right) d\left(S_{3}\right)+\int_{v o l} \delta T q d v o \emptyset\right)
$$


In the equation, ${ }^{\circ o l}$ refers to the element volume $\{L\}^{T}=\left[\frac{\partial}{\partial x} \frac{\partial}{\partial y} \frac{\partial}{\partial z}\right] ; q$ is the heat generation of unit volume; ${ }^{h_{f}}$ refers to convective heat transfer coefficient; $T_{B}$ is the temperature of fluid; $\delta_{T}$ is the dummy variable of temperature; $S_{2}$ is the application area of heat flux; $S_{3}$ is the application area of convection.

Polynomial of unknown temperatures:

$T=\{N\}^{T}\left\{T_{e}\right\}$

In the equation, $\left\{T_{e}\right\}$ refers to temperature vectors of element nodes; $\{N\}^{T}$ refers to the shape function of element.

Heat flux and temperature gradient of each element can be calculated according to temperatures of element nodes:

$\{a\}=\{L\}^{T}=[B]\left\{T_{e}\right\}$

In the equation, $\{a\}$ refers to the thermal gradient vector; $[B]=\{L\}^{T}[N]$

Heat flux can be calculated according to equation (7):

$\{q\}=(D)\{L\}^{T}=(D)[B]\left\{T_{e}\right\}=(D)\{a\}$

In the equation, $(D)$ refers to the property matrix of heat conduction of the material.

$$
\begin{aligned}
& \int_{v o l} \rho\left\{N_{\}}^{T}\{N\} d(v o)\left\{T_{e}\right\}+\int_{v o l} \rho\left\{N_{\}}^{T}\{v\}^{T}[B] d(v o)\left\{T_{e}\right\}+\int_{v o l}(B)^{T}(D)(B) d(v o)\left\{T_{e}\right\}=\right.\right. \\
& \int_{S_{2}}\{N\} q^{*} d\left(S_{2}\right)+\int_{S_{2}} T_{B} h_{f}\{N\} d\left(S_{3}\right)-\int_{S_{2}} h_{f}\left\{N^{T}\{N\}\left\{T_{e}\right\} d\left(S_{3}\right)+\int_{v o l} q d v o\right)
\end{aligned}
$$

Matrix form of the above equation is:

$$
\text { (C) }\{T\}+\left(\left(K^{m}\right)+\left(K^{d}\right)+\left(K^{c}\right)\right)\{T\}=\left(Q^{f}\right)+\left(Q^{c}\right)+\left(Q^{g}\right)
$$

In the equation:

$$
\begin{aligned}
& \left(K^{m}\right)=\int_{v o l} \rho c\{N\}^{T}\{v\}^{T}[B] d(\mathrm{vol}) \\
& \left(K^{d}\right)=\int_{v o l}(B)^{T}(D)(B) d(\mathrm{vol}) \\
& \left(K^{c}\right)=\int_{s_{2}} h_{f}\{N\}^{T}\{N\} d\left(S_{3}\right) \\
& \left(Q^{f}\right)=\int_{s_{2}}\{N\} q^{*} d\left(S_{2}\right) \\
& \left(Q^{c}\right)=\int_{S_{2}} T_{B} h_{f}\{N\} d\left(S_{3}\right) \\
& \left(Q^{g}\right)=\int_{v o l} q d(v o l)
\end{aligned}
$$


The general equation matrix can be expressed as:

(C) $\{T\}+(K)\{T\}=\{Q\}$

In the equation,

$$
(C)=\sum_{i=1}^{n}(C)_{i} \quad, \quad(K)=\sum_{i=1}^{n}\left(K^{m, d, c}\right)_{i}
$$

and

$(Q)=\sum_{i=1}^{n}\left\{Q^{f, c, g}\right\}_{i}+\left\{Q_{0}\right\}$

. $n$ refers to the number of elements; $\left\{Q_{0}\right\}$ refers to the rate of heat flow applied to nodes.

\section{Processing of phase change problems using the finite element software} ANSYS

ANSYS (Wang, 2014; Oluwole and Odunfa, 2015; Delele et al., 2013) is a kind of large scale and general finite element analysis software that integrates electric field, magnetic field, sound field, structure, load, temperature field and fluid analysis.

Finite element analysis software ANSYS considers the latent heat of phasechange materials through defining the enthalpy value of phase-change materials which changes along with the change of temperature. Changes of enthalpy value can be described by the function expression of density, specific heat and temperature.

$\Delta H=\int \rho C(T) d T$

Equation (11) indicates that, $\Delta H$ refers to the integral of the product of density and specific heat to temperature, and its unit is $\mathrm{J} / \mathrm{m}^{3}$.

Internal and external heat quantity of composite corrugated cases of fruits packaging system includes three parts: external high-temperature air transfers heat to the inside of boxes through the box wall $\left(q_{1}\right)$; heat brought by the gas exchange between side wall gaps of boxes inside the system $\left(q_{2}\right)$; respiratory heat produced by fruits $\left(q_{3}\right)$. The total heat $Q_{1}$ produced by above three methods after $h$ hours is $Q_{1}=h\left(q_{1}+q_{2}+q_{3}\right)=h\left[K A\left(T_{1}-T_{2}\right)+M\left(i_{i}-i_{2}\right)+2.553 G u\right]$

In equation (12), $K$ refers to the heat transfer coefficient $\left(k \mathrm{cal} /\left(\mathrm{m}^{2} \cdot h \cdot K\right)\right)$ of the whole box; $T_{1}$ and $T_{2}$ refer to the internal and external temperatures $\left({ }^{\circ} \mathrm{C}\right)$ of the box respectively; $A$ is the superficial area $\left(m^{2}\right)$ of the box; $M$ refers to the quality $(\mathrm{kg} / \mathrm{h})$ of heat exchange air every hour; $G$ refers to the quality $(\mathrm{kg})$ of fruits; $i_{1}$ and $i_{2}$ are specific enthalphy $(\mathrm{kcal} / \mathrm{kg})$ of the internal and external air of the box respectively; 
$u$ refers to the quality $(g)_{\text {of }} \mathrm{CO}_{2}$ produced by respiration of fruits in $1 \mathrm{~h}$. Suppose the freshness of fruits can be preserved for $\mathrm{h}$ hours at $\mathrm{T}{ }^{\circ} \mathrm{C}$, meaning that the color, aroma, taste and edible value of fruit are not affected. The endothermic process of fruits in the box is also a constantpressure process, thus the heat consumed by increase of $1{ }^{\circ} \mathrm{C}$ of fruits is constant-pressure specific heat $\left(C_{p}\right), Q_{2}$ refers to the quantity of heat consumed by the increase of fruits temperature from $T_{1}$ to $T$. Suppose other heat losses are ignored, then according to the law of conservation of energy, the total heat $Q_{1}$ input by external environment is equal to the heat $Q_{2}$ absorbed by fruits.

$Q_{1}=Q_{2}=G C_{p}\left(T-T_{1}\right)$

Heat-shielding performance of composite corrugated cases was simulated in this study; heated pure water (physical heat source) was used to replace the respiratory heat of fruits (biological heat source). Thus, according to equation (12) and (13):

$Q_{1}=h\left[K A\left(T_{1}-T_{2}\right)+M\left(i_{1}-i_{2}\right)\right]=c M_{1}\left(T-T_{1}\right)$

In equation (14), ${ }^{c}$ refers to the specific heat of water $\left(\mathrm{kcal} /\left(\mathrm{kg} \cdot{ }^{\circ} \mathrm{C}\right)\right)$ and $M_{1}$ refers to the quality $(\mathrm{kg})$ of heated pure water. Specific enthalpy of internal air and external air of the box is $i_{1}-i_{2}=(1.01+1.84 d)\left(T_{1}-T_{2}\right)$; $d$ refers to the relative humidity of air, thus the computational formula of heat conductivity coefficient $\mathrm{K}$ of the whole box can be obtained based on equation (14).

$$
K=\frac{c M_{1}\left(T-T_{1}\right)}{h A\left(T_{1}-T_{2}\right)}-\frac{M(1.01+1.84 d)}{A}
$$

The heat conductivity coefficient of composite corrugated box can be calculated according to equation (15).

\section{HEAT BALANCE OF REFRIGERATOR VAN}

A mechanical refrigerated car used for short-distance refrigerated transport was taken as the research object in this study. The size of the car which was length $\times$ width $\times$ height $=4.2 \mathrm{~m} \times 2.2 \mathrm{~m} \times 2.2 \mathrm{~m}$. Polyurethane extruded sheet was used as the thermal insulation material of the car and its thickness was $100 \mathrm{~mm}$. The refrigerating system was inside the car, which could adjust the temperature. 


\section{Heat balance method}

Heat balance method refers to considering all kinds of factors of dissipation of cooling capacity of the refrigerator car on the basis of the heat balance theory, and such method has accurate calculation, while it is also complicated in calculation of the thermal load of refrigerator. The total thermal load $Q$ of the refrigerator car is the sum of load from outside and the load produced inside the car, which includes following four parts:

(1) Heat $Q_{1}$ introduced from the outside environment

$Q_{1}=1.1\left(Q_{b}+Q_{s}+Q_{l}+Q_{d}\right)$

In equation (16), 1.1 refers to the loss coefficient.

$Q_{b}=K F\left(t_{e}-t_{i}\right)$

In equation (17), $Q_{b}$ refers to introduced heat quantity (W) through the car; $K$ refers to the overall heat transfer coefficient $\left(W /\left(m^{2} \cdot{ }^{\circ} \mathrm{C}\right)\right)$ of the car.

$$
F_{m}=\sqrt{F_{e} \cdot F_{i}}
$$

In equation (18), ${ }^{F_{m}}$ refers to the average heat transfer area $\left(m^{2}\right)$ of the car; $F_{e}$ is the exterior superficial area $\left(\mathrm{m}^{2}\right)$ of the car; $F_{i}$ is the interior superficial area $\left(\mathrm{m}^{2}\right)$ of the car; ${ }^{t_{e}}$ refers to the average temperature of environment $\left({ }^{\circ} \mathrm{C}\right)$ and ${ }^{t_{i}}$ is the average temperature inside the car $\left({ }^{\circ} \mathrm{C}\right)$. $Q_{s}=K F_{s} \Delta t_{s} \frac{\tau_{s}}{24}$

In equation (19), $Q_{s}$ refers to the heat quantity $(W)$ transferred into the car from solar radiation; $F_{s}$ refers to the area $\left(m^{2}\right)$ that affected by solar radiation; ${ }^{\Delta t_{s}}$ refers to the increase of temperature $\left({ }^{\circ} \mathrm{C}\right)$ under the effect of solar radiation; ${ }^{\tau_{s}}$ is the time of solar radiation.

$$
Q_{1}=\beta \cdot Q_{b}
$$

In equation (20), $Q_{1}$ refers to heat quantity ( $W$ ) introduced by air permeation; $\beta$ refers to the additional heat load coefficient of air permeation.

$Q_{d}=f \cdot\left(Q_{b}+Q_{s}\right)$

In equation (21), $Q_{d}$ refers to heat quantity $(W)$ introduced by the open of car door; $f$ refers to the additional heat load coefficient of door opening 
(Table 1 shows the additional heat load coefficient of door opening during transport).

(2) Cooling capacity $Q_{2}$ consumed by the thermal insulation material and the precooling of components is:

$$
Q_{2}=\frac{1}{2} \sum(G \cdot C) \Delta t / \Delta \tau
$$

In equation (22), $G$ refers to the quality $(\mathrm{kg})$ of thermal insulation materials or car components; $C$ refers to corresponding specific heat $\left(\mathrm{kJ} /(\mathrm{kg} \cdot)^{\circ} \mathrm{C}\right)$.

Table 1. Additional heat load coefficient of door opening

\begin{tabular}{|l|l|}
\hline Opening frequency (times) & Additional heat load coefficient $f$ \\
\hline 0 & 0.25 \\
\hline $1-5$ & 0.5 \\
\hline $6-10$ & 0.75 \\
\hline $11-15$ & 1 \\
\hline
\end{tabular}

(3) The cooling capacity $Q_{3}$ consumed by the precooling of products is $Q_{3}=G_{f} \cdot C_{f} \Delta t / \Delta \tau$

In equation (23), ${ }^{G_{f}}$ refers to the quality $(\mathrm{kg})_{\text {of products; }} C_{f}$ is the specific heat $\left(\mathrm{kJ} /(\mathrm{kg} \cdot)^{\circ} \mathrm{C}\right)$ of products.

(4) Heat quantity $Q_{4}$ produced inside the car is

$Q_{4}=Q_{f}+Q_{i}$

$Q_{f}=G_{f} \cdot q_{f}$

In above equations, $Q_{f}$ refers to the heat release ( $W$ ) of products (respiratory heat of vegetables, etc.); ${ }^{q_{f}}$ refers to the heat $(\mathrm{W} / \mathrm{kg}$ ) released by products per kilogram per hour.

$Q_{i}=P_{i} \cdot t_{i} \cdot \frac{1}{24}$

In the equation (26), ${ }^{Q_{i}}$ refers to heat quantity $\left({ }^{W}\right)$ produced by illumination inside the car; ${ }^{P_{i}}$ refers to the power ( $W$ ) of lighting; ${ }^{t_{i}}$ refers to the illuminating period $(W)$.

Finally, the total heat load of the refrigerator car can be obtained.

$Q=Q_{1}+Q_{2}+Q_{3}+Q_{4}$ 
During the transportation of the eutectic plate refrigerated car, the cooling consumption amount is balanced by melting of eutectic ice, thus to maintain the low temperature inside the car and guarantee the quality of fresh products.

\section{Stacking of refrigerated products inside the car}

Spaces between products and products and the car wall should be guaranteed because good heat exchange and temperature require good ventilation. Figure 1 shows a way of stacking products; A1 refers to the car body; A2 A9 refers to the stacking area; each stacking area has a push plate; each push plate is placed with three layers of products and each layer is placed with two packing boxes; the space between car roof and the top of third layer is $10 \mathrm{~cm}$; the distance between boxes and car wall is $15 \mathrm{~cm}$; the distance between A2 and A6 and the car tail is $20 \mathrm{~cm}$; the distance between A5 and A9 and front of car is $30 \mathrm{~cm}$; the line spacing and row spacing are $10 \mathrm{~cm}$ and $20 \mathrm{~cm}$ respectively (Defraeye et al., 2015).

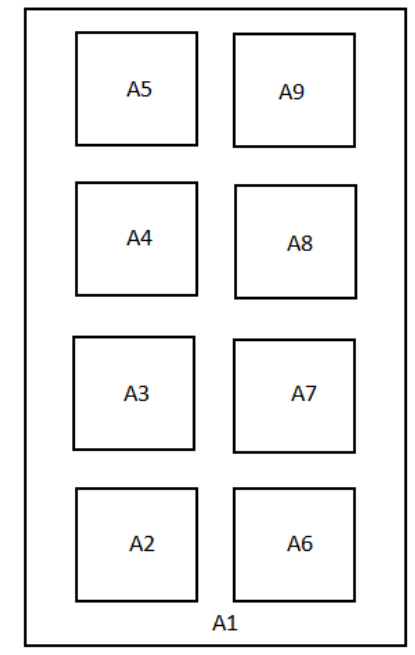

Figure 1. Stacking of products

\section{HEAT PRODUCED BY CAR DURING THE PROCESS OF TRANSPORTATION}

Heat $Q$ produced by the refrigerator car during transportation can be divided into two kinds: heat $Q_{1}$ produced by heat loss trough insulation or door opening during transportation, and heat $Q_{2}$ caused by thermal radiation of the sun. The calculation equations are as follows:

$Q_{1}=\lambda_{0} S \Delta T$ 
In above equations, ${ }^{\lambda_{0}}$ refers to the heat conductivity of the car, which is $0.55(\mathrm{~W} /(\mathrm{mK})) ; S$ refers to the heat exchange area of car $\left(m^{2}\right) ; \Delta T$ is the temperature difference $(\mathrm{K})$ inside and outside the car; $\Delta T^{\prime}$ is the temperature difference $(\mathrm{K})$ between car surface and the inside of car; $Z$ is environmental coefficient.

\section{SIMULATION OF TEMPERATURE FIELD INSIDE THE REFRIGERATOR CAR}

Using ANSYS FLOTRAN software, this study simulated and analyzed the temperature field inside the refrigerator car (Zhou, 2010; Elnaggar et al., 2013).

\section{Modeling and grid generation}

Construction of models is accomplished by the modeling module of ANSYS software. The top view of car is drawn by using Solid 8node77 for grid generation. A2, A3, A4, A5, A6, A7 and A8 are spaces for corrugated boxes. Gas flow space of the car and the overall space of the car are given grid generation (Mamun and Stokes, 2014; Luo, 2014; Spano and Stara, 2008).

\section{Definition of material parameters}

Parameters of products (Xiao and Liu, 2011)

Bergamot pears were used as the research objects in this study, because bergamot pears had regular shapes, thus spaces between pears could be left after pears were placed in boxes, which made the simulation results much closer to the reality.

The shape of bergamot pears was taken as a sphere approximately in this study and the diameter was $\mathrm{D}=60 \mathrm{~mm}$; the heat conductivity of the bergamot pear was $\lambda=0.14 \mathrm{~W} /(\mathrm{m} \cdot \mathrm{K})$.

Suppose bergamot pears occupied $60 \%$ of the volume in each corrugated box; porosity $\zeta=0.4$; density of bergamot pears is $\rho=700 \mathrm{~kg} / \mathrm{m}^{3}$ and the specific heat capacity of bergamot pears $C=2.45 \mathrm{KJ} /(\mathrm{kg} \cdot \mathrm{K})$. Appropriate temperature for transportation of bergamot pears is $5^{\circ} \mathrm{C}$.

Physical property parameters of the cold air in car

The operating parameters of the refrigerating equipment in the compartment are shown in Table 2. From the above, it can be seen that the optimum 
transport temperature of bergamot pear is $5^{\circ} \mathrm{C}$, so $5^{\circ} \mathrm{C}$ is set to be the initial temperature. As there was a certain temperature difference inside and outside the refrigerated car as it began to transport, the cooling equipment operating temperature is set to be $0{ }^{\circ} \mathrm{C}$ or $3{ }^{\circ} \mathrm{C}$ to quickly cool the interior compartment. By comparing the two operating temperatures, a more reasonable mode of transport was obtained.

Scheme 1: taking $0{ }^{\circ} \mathrm{C}$ as the operating temperature, 5 minutes after cooling, the temperature inside the compartment reached about $5{ }^{\circ} \mathrm{C}$; After cooling for 15 minutes, the maximum temperature in the compartment was $4^{\circ} \mathrm{C}$; the maximum temperature of the corrugated box in the carriage center was 3 ${ }^{\circ} \mathrm{C}$, lower than the pear's best transport temperature. In order to keep the compartment temperature at the optimum transport temperature for the pear, the refrigeration system was turned off and the temperature inside the compartment was kept under constant attention. The temperature of the pears in the compartment was close to $5 \mathrm{C}$ after 20 minutes of shutdown.

Scheme 2: taking $3^{\circ} \mathrm{C}$ as the operating temperature, 5 minutes after cooling, the temperature inside the compartment reached about $6^{\circ} \mathrm{C}$; After cooling for 10 minutes, the maximum temperature in the compartment was $4.5^{\circ} \mathrm{C}$; the maximum temperature of the corrugated box in the carriage center was $2.7{ }^{\circ} \mathrm{C}$, lower than the pear's best transport temperature. In order to keep the compartment temperature at the optimum transport temperature for the pear, the refrigeration system was turned off and the temperature inside the compartment was kept under constant attention. The temperature of the pears in the compartment was close to $5^{\circ} \mathrm{C}$ after 15 minutes of shutdown.

Table 2. Physical properties under compartment cooling

\begin{tabular}{|c|c|c|c|}
\hline $\begin{array}{l}\text { Working } \\
\text { temperature } \mathrm{t}( \\
\left.{ }^{\circ} \mathrm{C}\right)\end{array}$ & $\begin{array}{l}\text { Refrigerating } \\
\text { capacity (W) }\end{array}$ & $\begin{array}{c}\text { Air density } \\
\left(\mathrm{kg} / \mathrm{m}^{3}\right)\end{array}$ & $\begin{array}{l}\text { Air thermal } \\
\text { conductivity } \lambda \\
(W /(m \cdot K))\end{array}$ \\
\hline 0 & 1050 & \multirow[t]{2}{*}{1.228} & \multirow[t]{2}{*}{0.16} \\
\hline 3 & 900 & & \\
\hline $\begin{array}{l}\text { Air thermal } \\
\text { expansion } \\
\text { coefficient } \beta \\
(l / K)\end{array}$ & $\begin{array}{l}\text { Air dynamic } \\
\text { viscosity } \\
\text { coefficient } \\
\left.\text { (N.s/ } m^{2}\right)\end{array}$ & $\begin{array}{l}\text { Air specific heat } \\
\text { capacity } C \\
(K J /(\mathrm{kg} \cdot \mathrm{K}))\end{array}$ & $\begin{array}{l}\text { cold air outlet } \\
\text { wind speed } v \\
(m / s)\end{array}$ \\
\hline 3.378 & $1.85 \times 10^{-5}$ & 2.62 & 1 \\
\hline
\end{tabular}

\section{Results of simulation and analysis}

The temperature field of the corrugated box inside the refrigerating 
equipment under the two schemes is shown in Figure 2.

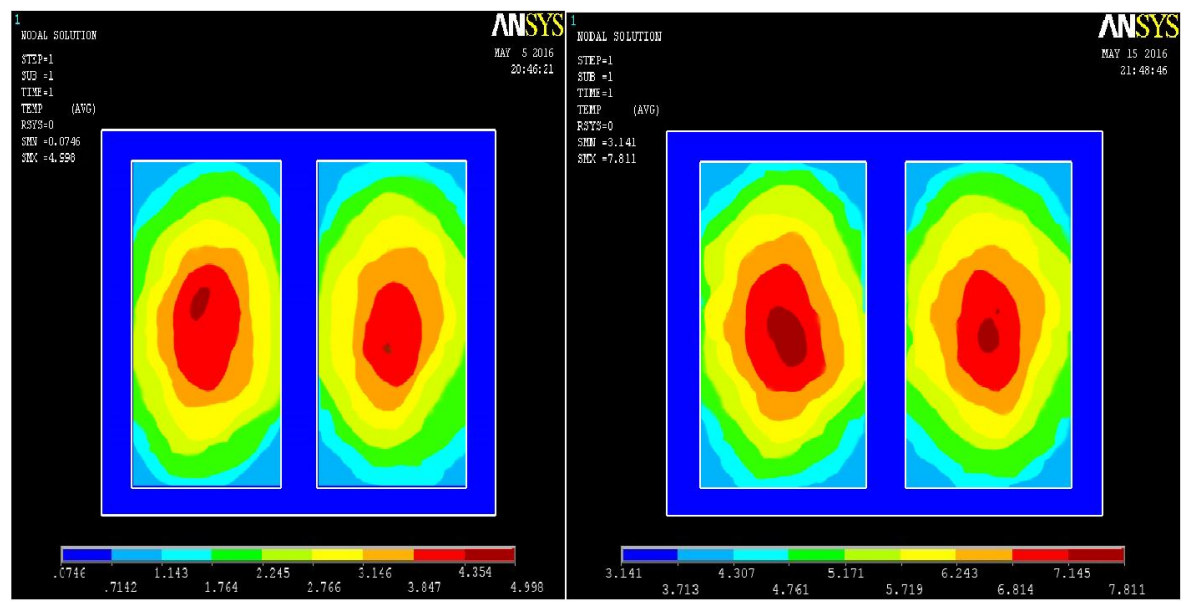

Figure 2. The temperature field of the corrugated box inside the refrigerating equipment under the two schemes $\left(0^{\circ} \mathrm{C}, 3^{\circ} \mathrm{C}\right)$

Average temperatures of the products in the car at different cryogenic temperatures are shown in Figure 3.

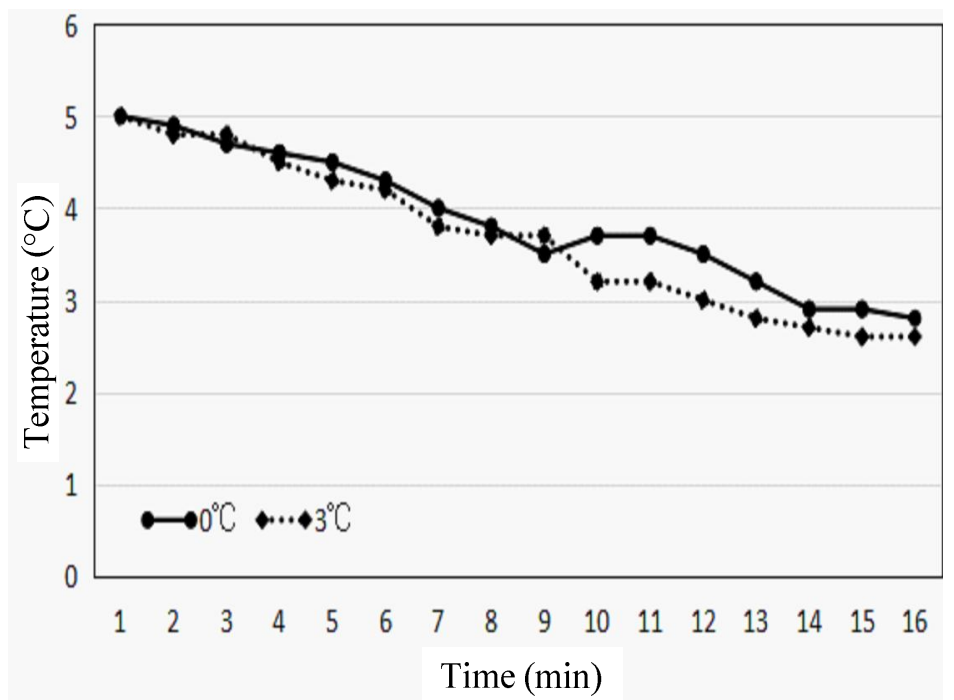

Figure 3. Mean temperature change during refrigerated transport

Figure 3 shows that, the temperature changes of the products during transportation are non-linear. The total distance covered by the refrigerator car was $120 \mathrm{~km}$, which takes $2 \mathrm{~h}$; during the transportation, different temperatures inside the car could lead to different consumption of energy. Specific data are shown in Table 3. 
Table 3. Energy consumption in different refrigerating methods

\begin{tabular}{|c|c|c|}
\hline Refrigerating temperature $\left({ }^{\circ} \mathrm{C}\right)$ & $0{ }^{\circ} \mathrm{C}$ & $3{ }^{\circ} \mathrm{C}$ \\
\hline Time of refrigeration & 4 & 5 \\
\hline Average temperature of the product & $4.136{ }^{\circ} \mathrm{C}$ & $4.172^{\circ} \mathrm{C}$ \\
\hline Energy consumption $(\mathrm{KJ})$ & $3.75 \times 10^{3}$ & $2.74 \times 10^{3}$ \\
\hline
\end{tabular}

Data in table 3 show that, in the first kind of refrigerating method, the refrigerating temperature was $0{ }^{\circ} \mathrm{C}$ and the refrigerating time was 15 min for each time, $20 \mathrm{~min}$ of pause between each time, thus the overall operating time of the refrigerating system was $60 \mathrm{~min}$, the average temperature of the product was $4.1366^{\circ} \mathrm{C}$ and energy consumption was $3.75 \mathrm{X} 10^{3} \mathrm{KJ}$; in the second kind of refrigerating method, the refrigerating temperature was $3{ }^{\circ} \mathrm{C}$ and the refrigerating time was $10 \mathrm{~min}$ for each time, $15 \mathrm{~min}$ of pause between each time, thus the overall operating time of the refrigerating system was $50 \mathrm{~min}$, the average temperature of the product was $4.172^{\circ} \mathrm{C}$ and the energy consumption was $2.74 \mathrm{X}^{10^{3}} \mathrm{KJ}$. Obviously, the second method not only satisfied the low-temperature operation, but also saved 1. $01 \mathrm{X}$ $10^{3} \mathrm{KJ}$ of energy consumption, which decreased by $26.9 \%$ and reduced transportation costs. Thus the second method was more appropriate for refrigeration.

\section{CONCLUSIONS}

This study analyzes heat balance of corrugated boxes based on elementary knowledge of heat transfer theory, and the heat balance equation of corrugated boxes is constructed on the basis of heat transfer process of corrugated boxes, heat exchange of ventilation hole and respiratory heat of products. Different schemes are used to ensure the optimization of food refrigeration packaging. Some of the minor parameters are neglected in the thermal analysis of products, such as the self respiration heat of different fruits and vegetables, thus this study has certain limitations.

\section{REFERENCES}

1. Defraeye, T., Verboven, P., Opara, U. L., et al. (2015). Feasibility of ambient loading of citrus fruit into refrigerated containers for cooling during marine transport. Biosystems Engineering, Vol.134, pp.20-30.

2. Delele, M. A., Ngcobo, M. E. K., Opara, U. L., et al. (2013). Investigating the Effects of Table Grape Package Components and Stacking on Airflow, Heat and Mass Transfer Using 3-D CFD 
Modelling. Food \& Bioprocess Technology, Vol.6, No.9, pp.25712585.

3. Elnaggar, M. H. A., Abdullah, M, Z., Munusamy, S. R. R., (2013). Experimental and Numerical Studies of Finned L-Shape Heat Pipe for Notebook-PC Cooling. IEEE Transactions on Components Packaging \& Manufacturing Technology, Vol.3, No.6, pp.978-988.

4. Jaremkiewicz, M., (2014). Determination of transient fluid temperature using the inverse method. Archives of Thermodynamics, Vol.35, No.1, pp.61-76.

5. Jedermann, R., Ruiz-Garcia, L., Lang, W., (2009). Spatial temperature profiling by semi-passive RFID loggers for perishable food transportation. Computers \& Electronics in Agriculture, Vol.65, No.2, pp.145-154.

6. Jia, K., (2013). Design of Wireless Sensor Node in Cold Chain Transportation Monitoring. Transactions of the Chinese Society for Agricultural Machinery, Vol.44, No.2, pp.136-141.

7. Liu, L., Hu, J., Zhang J., et al. (2010). Development of TimeTemperature Data Collection Program for Frozen Fish in the Cold Chain. Sensor Letters, Vol.8, No.1, pp.47-51.

8. Luo, Z. B., (2014). Effects of Different Vents Location on flow Characteristics of Air Conditioning. Applied Mechanics \& Materials, Vol.662, pp.179-182.

9. Mamun, K. A., Stokes, J., (2014). Development of a semi automated dual feed unit to produce FGM coatings using the HVOF thermal spray process. South Pacific Journal of Natural \& Applied Sciences, Vol.32, No.1, pp.18-26.

10. Mikielewicz, D., Andrzejczyk, R., Jakubowska, B., et al. (2014). Comparative study of heat transfer and pressure drop during flow boiling and flow condensation in minichannels. Archives of Thermodynamics, Vol.35, No.3, pp.17-37.

11. Mikielewicz, D., Muszyński, T., Mikielewicz, J., (2012). Model of heat transfer in the stagnation point of rapidly evaporating microjet. Archives of Thermodynamics, Vol.33, No.1, pp.139-152.

12. Net, M.,Trias, E., Navarro, A., et al. (2003). Cold chain monitoring during cold transportation of human corneas for transplantation. Transplantation Proceedings, Vol.35, No.5, pp.2036-2038.

13. Oluwole, L., Odunfa, A., (2015). Investigating the effect of ocean waves on Gravity Based offshore platform using Finite Element Analysis Software ANSYS. International Journal of Scientific \& 
Engineering Research, Vol.6, No.8, pp.24-33.

14. Spano, M., Stara, V., (2008). Application of a 2D Turbulence Model for Estimation of the Discharge Coefficient on Round - shaped Weirs. Aip Conference Proceedings, Vol.1048, No.1, pp.806-809.

15. Tan, Y. B., Zhang, Q. Y., (2014). Food cold chain transportation management based on grid technology. Applied Mechanics \& Materials, Vol.543-547, pp.4540-4542.

16. Vasiliev, L., Vasiliev, L., Zhuravlyov, A., et al. (2015). Vapordynamic thermosyphon - heat transfer two-phase device for wide applications. Archives of Thermodynamics, Vol.36, No.4, pp.65-76.

17. Wang, F. C., Jun-Guo, L. I., Dong, Y. C., et al. (2012). Research Progress of Application of Polysaccharides and Modified Polysaccharides in Film Coatings for Food Preservation. Food Science, Vol.33, No.5, pp.299-304.

18. Wang, J. L., (2014). Based on the Finite Element Software ANSYS/LS-DYNA Metal Plate Covering Parts Forming Process Simulation and Optimization Research. Advanced Materials Research, Vol.912-914, pp.589-592.

19. Xiao, Y., Liu, D., (2011). Agricultural Products Refrigerated and Insulated Transport Technology and Equipment Research. Journal of Agricultural Mechanization Research, Vol.33, No.1, pp.57-60.

20. Yue, J., Liu, L., Li, Z., et al. (2013). Improved quality analytical models for aquatic products at the transportation in the cold chain. Mathematical \& Computer Modelling, Vol.58, No.s3-4, pp.474-479.

21. Zhang, B. N., Zhu, X. Y., Lai, J., (2011). Effect of Ozone Water Treatment on Preservation of Chinese Chestnut Fruits during Storage. Food Science, Vol.32, No.16, pp.361-364.

22. Zhang, Z., Gao, Z., Min, L. I., et al. (2013). Effect of Food Additives on Postharvest Pathogens and Preservation of Mango Fruit. Chinese Journal of Tropical Crops, Vol.34, No.11, pp.2289-2294.

23. Zhou, Y., (2010). Effect of Velocity of Fluid Field of 3-Spacer Nozzle in Roll-Casting Models Using Coupled Fluid-Thermal Finite Element Analysis. Applied Mechanics \& Materials, Vol.29-32, pp.1481-1487. 
